\title{
XLV. Notes on the absorption of X-rays
}

\section{Tycho E:son Aurén Dr. phil.}

To cite this article: Tycho E:son Aurén Dr. phil. (1917) XLV. Notes on the absorption of X-rays , Philosophical Magazine Series 6, 33:198, 471-487, DOI: 10.1080/14786440608635661

To link to this article: http://dx.doi.org/10.1080/14786440608635661

$$
\text { 册 Published online: } 08 \text { Apr } 2009 .
$$

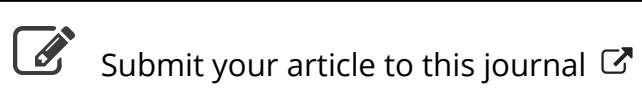

\footnotetext{
Џll Article views: 2
}

Q View related articles $\square$

Citing articles: 1 View citing articles $\square$ 
12. The classification which has been adopted for the tracks of particles moving at $10 \mathrm{~m} . / \mathrm{s}$. holds good for all velocities comparable with wind-velocities and therefore of practical interest. It may be noted, however, that for sufficiently great velocities the classification would break down. Cases III. $a, b$, and Case II. become identical for the path which crosses the pole and is asymptotic to the equator. Such a particle tends to a position of rest relative to axes fixed in space, and it follows that the velocity of projection from the pole must be equal to the absolute velocity of a point on the equator.

Cases III. $c$ and $d$ are possible when the relative velocity does not exceed twice the absolute velocity of a point on the equator. For velocities above that limit all tracks cross the equator.

$\mathrm{XLV}$. Notes on the Absorption of X-Rays. By Trgho E:son Aurḱn, Dr.phil.*

\section{Introduction.}

THE coefficient $(\mu)$ for the absorption of $X$-rays is found by means of the law

$$
\mathrm{I}=\mathrm{I}_{0} e^{-\mu d} \text {, . . . . . . }
$$

where $I_{0}$ is the intensity of the incident rays, $I$ that of transmitted rays, and $d$ the thickness of the sheet of a definite material. As the above law only holds under the condition that radiation is homogeneous, and a perfectly homogeneous radiation of sufficient intensity is not easily brought about, there arise, already from this cause, serious difficulties as to the exact determination of absorption coeffieients. Moreover, other difficulties are presented by the fact that the intensity of radiation in the bulb is continually changing, and that the intensity of the rays will be diminished not only by absorption but also by scattering. Thus the determinations made, up to this date, of absolute absorption coefficients seem to be rather uncertain $\dagger$. Nowadays, the ratio of absorption is expressed by the mass-absorption coefficient $\left(\frac{\mu}{\sigma}\right)$, which is obtained by dividing the absorption coefficients by the density $(\sigma)$ of the absorbing material.

W. H. Bragg and Pierce $\dagger$ have, instead of the coefficient

* Communicated by the Author.

† Compare Bragg and Pierce, Phil. Mag. xxviii. p. 626 (1914). 
just montioned, made use of the atomic absorption coefficient that expresses the proportion of the energy of an $\mathrm{X}$-ray pencil which is absorbed on crossing a surface on which lies one atom to every square centimetre. This kind of expression will in many cases be preferable to the massabsorption coefficient, because the atomic absorption coefficient can be more easily than that coefficient compared with other characteristic constants of the atom. As the mass of an atom can be easily calculated $\frac{\mu}{\sigma}$ is obtained by dividing the atomic absorption coefficient by the mass of the corresponding atoms.

The relation of the absorption coefficient and the wavelength $(\lambda)$ can be expressed approximately by the formula

$$
\frac{\mu}{\sigma}=\mathrm{A} \lambda{ }^{x}, \ldots \text {. . . . . . }
$$

where $\mathrm{A}$ and $x$ are constants. $x$ seems to have the same value (about 3 ) in all materials.

The relation of the atomic absorption coefficient $(\alpha)$ and the atomic number is given by Bragg and Pierce in the formula

$$
\alpha=\mathrm{CN}^{4} \lambda^{5 / 2}, \text {. . . . . . }
$$

where $\mathrm{C}$ is a constant and $\mathrm{N}$ the atomic number.

From the formula (2), it follows that the ratio of the absorption coefficients of two materials must be constant, $i . e$. independent of the wave-length, and according to the formula (3), this ratio might be expressed by the ratio of the fourth powers of the atomic numbers of the respective elements. The fact that the ratio in question is really constant in the case of rays of widely different wave-lengths was first pointed out by Barkla and Sadler * and, later on, it has been confirmed by Bragg and Pierce $\dagger$.

In the following table, the values found by the last-named scientists for the ratio of the atomic absorption coefficients of a few elements are compared partly with the corresponding values which I have calculated from the values found by Barkla and Sadler of the mass-absorption coefficients, partly with the values I have found by means of the method mentioned below. In column 1 are noted the average values found by Bragg and Pierce by means of the characteristic rays from $\mathrm{Ag}, \mathrm{Rh}, \mathrm{Pd}$; in column 2 , those found by Barkla and Sadler by similar radiation from $\mathrm{Ag}$; and in

* Barkla and Sadler, Phil. Mag. xvii. p. 739 (1909).

+ Bragg and Pierce, loc. cit. 
column 3 , those found by the same scientists by characteristic radiation from $\mathrm{Cr}, \mathrm{Fe}$, and Co ; and in column 4, those found by myself, by using non-homogeneous rays from an $\mathrm{X}$-ray bulb with an anticathode of tungsten which have been filtered through an aluminium screen :-

Table I.

\begin{tabular}{|c|c|c|c|c|}
\hline \multirow[t]{2}{*}{ Elements. } & \multirow{2}{*}{$\begin{array}{l}1 . \\
\text { Bragg and Pierce } \\
\text { with rays from } \\
\text { Ag, Rh, Pd. }\end{array}$} & \multicolumn{2}{|c|}{\begin{tabular}{c|c}
2. & 3. \\
Barkla and Sadler \\
with rays from
\end{tabular}} & \multirow{2}{*}{$\begin{array}{c}4 . \\
\text { Aurén } \\
\text { with non- } \\
\text { homogeneous } \\
\text { rays. }\end{array}$} \\
\hline & & Ag. & $\mathrm{Cr}, \mathrm{Fe}, \mathrm{Co}$ & \\
\hline $\mathrm{F} \theta / \mathrm{Al}$ & 152 & $14 \cdot 3$ & 169 & $13 \cdot 4$ \\
\hline $\mathrm{Ni} / \mathrm{F}_{\theta} \ldots .$. & $1 \cdot 30$ & $1 \cdot 37$ & $1 \cdot 22$ & $1 \cdot 30$ \\
\hline $\mathrm{Cu} / \mathrm{Ni}$ & $1 \cdot 17$ & $1 \cdot 15$ & $1 \cdot 21$ & $1 \cdot 10$ \\
\hline $\mathrm{Zn} / \mathrm{Cu}$ & $1 \cdot 13$ & $1 \cdot 14$ & 122 & $1 \cdot 15$ \\
\hline $\mathrm{Pt} / \mathrm{Al} \ldots \ldots$ & 163 & & $27 \cdot 7$ & 156 \\
\hline Pt/Ag... & $7 \cdot 64$ & $7 \cdot 69$ & $1 \cdot 61$ & $1 \cdot 76$ \\
\hline $\mathrm{Sn} /$ & $1 \cdot 33$ & $1 \cdot 37$ & $1 \cdot 37$ & $1 \cdot 04$ \\
\hline $\mathrm{Au} / \mathrm{Pt}$ & 1.05 & $1 \cdot 10$ & {$[1 \cdot 06]$} & $1 \cdot 02^{*}$ \\
\hline $\mathrm{Au} / \mathrm{Cu} \quad \ldots$ & $7 \cdot 28$ & $7 \cdot 86$ & {$[11 \cdot 8]$} & $8 \cdot 29^{*}$ \\
\hline
\end{tabular}

* $A u=540$ from curve, fig. 2.

The agreement between the various experiments is, on the whole, remarkably good, and where sensible changes have been observed they may easily be accounted for. Within the range of selective absorption, this law does not hold, and, from what I have found, neither does it hold when rays of greater wave-length (soft rays) are examined. Though the agreement between the values of the first, second, and fourth columns, in all cases but one, is good, the values of the third column differ from those in regard to the combinations $\mathrm{Fe} / \mathrm{Al}$ and $\mathrm{Pt} / \mathrm{Al}$, which are too low. As for the combination $\mathrm{Pt} / \mathrm{Ag}$, the values in the first and second columns agree between themselves, but these values do not agree with the values in the third and fourth columns, which, on the other hand, closely agree between themselves. The cause of the want of agreement between the said couples certainly depends on the fact that one of the constituent metals of the combination enters into the range of selective absorption in using the radiation in question. As it appears from the experiments of Barkla and Sadler, it is not here the case that the relation between the absorption coefficients is independent of the wave-length.

The ratio of the atomic and molecular absorption coefficients respectively is, in the ensuing pages, expressed by Phil. Mag. S.•6. Vol. 33. No. 198. June 1917. 2 L 
X.a.k. and X.m.k., and the absorption coefficient of the element in question is always compared with the absorption coefficient for water. Since, as shown above, the relative ahsorption coefficients are independent of the wave-length, and so are more easily to be exactly determined than the absolute absorption coefficients, and since they, as a rule, in different elements, plainly differ from each other, the relative atomic or molecular absorption coefficients may probably very well have the faculty of characterizing different species of atoms or molecules.

In making the inquiries which I am going to describe in the following pages I have tried to determine the relative absorption coefficients for several elements. As it has been found possible to determine the wanted constants in solutions, and as many elements are attainable without difficulty in the form of solutions, whereas they cannot at all or only with difficulty be obtained in solid or gaseous state, under conditions to allow the examining of absorption, I have chiefly made use of solutions. From the many experiments made on the absorption of X-rays, we infer that. "Though the experiments undertaken in cases of different density, temperature, and chemical combination may not nearly possess the required degree of experimental accuracy so as to eliminate every influence on absorbability, it may be stated as certain that the power of absorption is essentially determined by the properties of the atom "*. In calculating the relative atomic absorption coefficients from the values of the molecular absorption coefficients of the elements examined, I have, consequently, started from the principle that the absorption of the solution is additively determined by the absorption of the constituent atoms.

\section{Method of Investigation.}

In order to exclude errors due to incessant changes in hardness and intensity of the radiation, as well as only to have to make null-point-adjustments, my experiments have been arranged in the following manner. Two pencils of rays have been made to pass, one through the element the $\mathrm{X} . \mathrm{m} . \mathrm{k}$. of which is to be determined, and the other through a sheet of water the thickness of which could be varied. The thickness of the water sheet is regulated so that the intensity of both the pencils of rays is equally great. This, on the other hand, can be determined by observing when the currents of saturation in two ionization-chambers, into which

* Pohl, Die Physik der Röntgenstrahlen, p. 91 (1912). 
the two pencils of rays are allowed to penetrate, become equally strong. By combining the ionization-chambers with each other so as to make the two saturation currents neutralize each other, the null-point method can be used. After determining the thickness of the water sheet the relation between the absorption coefficients of the element examined and of water is easily found. The experimental arrangements are more plainly made out by the

Fig. 1.

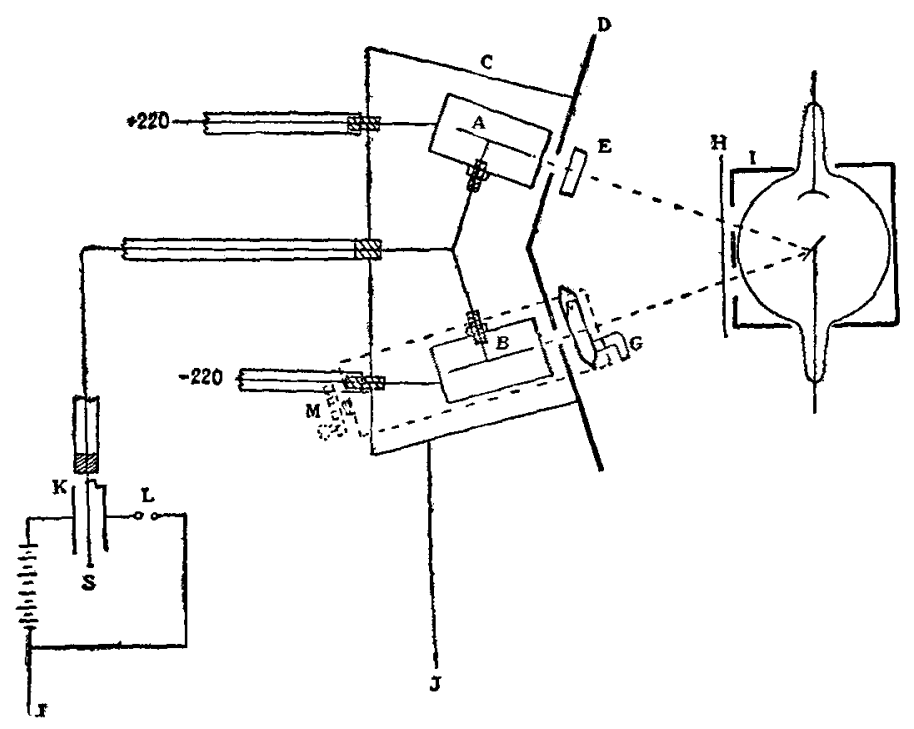

schematic figure (fig. 1) above. The two ionization-chambers (A and B), consisting of metallic boxes, in which as electrodes, insulated from the boxes by sulphur, metal sheets are fixed, and each of which is supplied with a mica window $(2.5 \mathrm{~cm}$. diam.), are, by way of avoiding influence from the bulb and from the high-tension wires, placed in a large earthed metal box (C), the front of which is a lead screen (D). Just in front of the said mica windows, apertures are made in the lead screen, and before these, there are two absorption vessels ( $E$ and $F$ ) at a distance of $4 \mathrm{~cm}$. from the respective ionization-chambers. In one of these are the parallel walls, bounding the liquid sheet to be examined, at a distance of $1 \mathrm{~cm}$. from each other, and made of thin mica, whereas the other walls are made of glass. The vessel 
is furnished with two additional pipes, one in the lower and the other in the upper part of it. By means of a short tubing the lower one is connected with a vessel containing the liquid to be examined. The other pipe is applied for the purpose of sucking up the liquid into the vessel. The other absorption vessel, that in what follows is designated as the comparator (F), consists of two parallel brass laminæ, provided with round apertures $(3 \mathrm{~cm}$. diam.), covered with thin mica, and the borders of these laminæe are connected by rubber cloth so that a water-tight bag is obtained. To the front Inmina is applied an additional tube $(G)$, that communicates by a rubber tube with a water-cistern, from which the vessel is supplied with water. The two brass laminæe are firmly fixed in a dividing machine (M), so that by the aid of the screw of the machine they may be caused to slide on each other, and so the thickness of the water be changed, and this change be accurately determined. The bulb, consisting of a Siemens tungsten tube with fin radiator for cooling the anticathode, through which passes a current of $0.5-1$ milliampere, is placed in a box (I), coated with lead, and furnished with two apertures directly in front of the two absorption vessels. For the purpose of filtering, an aluminium screen $(\mathrm{H}) 1.25 \mathrm{~mm}$. thick is applied. The ionization-chambers are charged up to +220 and -220 volts respectively, and the electrodes in them are connected with each other as well as with a stringelectrometer $(\mathrm{K})$ of Lutz-Edelmann, in which there is a Pt-string of $0.001 \mathrm{~mm}$. thickness. The sensibility of the electrometer amonnted to about 1 volt for one division of the scale. All the conductors are protected by metal tubes, which are earthed $(J)$, and the electrometer-string $(\mathrm{S})$ also, by means of a simple key (L), can be earthed. As current source for the bulb, I have used a high-tension transformer of Siemens' construction.

The determinations were carried out in the following manner. The absorption vessel is first filled with water, whereupon this, as well as the water-filled comparator, was exposed to radiation. The electrometer-string having been momentarily earthed, it is observed to which side the string seems to be moving. By augmenting or diminishing the thickness of the water-sheet in the comparator, radiation in the two ionization-chambers can be made to be equal in strength, in which case the currents neutralize each other, and the electrometer-string will remain at rest. The position of the screw $\left(d_{1}\right)$ is read, whereupon the water of the absorption vessel is exchanged for the solution whose ab. sorption coefficient has to be determined, the comparator is 
readjusted, and the position $\left(d_{2}\right)$ of the screw is read again. The change of the thickness of the water-sheet $\left(d_{2}-d_{1}\right)$ depends evidently on the difference of absorption in the solution and of a water-sheet of the same thickness $(1 \mathrm{~cm}$.). If we suppose the intensity of the incident rays at the absorption vessel to be $I$ and at the comparator $k \mathrm{I}$, and the absorption coefficients of water and the solution to be $\mu_{w}$ and $\mu_{s}$ respectively, then it follows, after the first adjustment, that

$$
\mathrm{I} e^{-\mu_{w}}=k \mathrm{I} e^{-\mu_{w} d_{1}},
$$

and after the second adjustment, that

$$
\mathrm{I} e^{-\mu_{s}}=k \mathrm{I} e^{-\mu_{x} d_{2}},
$$

whence it follows that

$$
\mu_{s}-\mu_{w}=\mu_{w}\left(d_{2}-d_{1}\right) ;
$$

or, when the absorption coefficient of the dissolved substance $\left(\mu_{x}\right)=\mu_{s}-\mu_{w}$

$$
\frac{\mu_{x}}{\mu_{\mathfrak{w}}}=d_{2}-d_{1} \text {. }
$$

Now X.m.k. $(\rho)$ is readily found if the number of molecules in one litre is calculated. Since pure water contains 55.5 gram-molecules $\mathrm{H}_{2} \mathrm{O}$, and the solution $m$ gram-molecules of the dissolved substance per litre, we obtain

$$
\rho=\frac{\left(d_{2}-d_{1}\right) 55 \cdot 5}{m} . \quad . \quad . \quad . \quad .
$$

This formula presupposes that the water quantum of the solution is the same as that of pure water, which case only can be thought correct when working with diluted solutions. When working: with highly concentrated solutions, a correction for the wanting water quantum must be made. This correction is readily calculated when the specific weight of the solution is known. The value of $d_{2}$ is augmented by the thickness of the water sheet that should be added in order to keep the water quantum of the absorption vessel unaltered. Although, no doubt, part of the rays, scattered from the absorption vessels, have penetrated into the ionization-chambers, no special correction of the fault originating from this source has been made. The intensity of the scattered rays must needs be thought almost equal, because the density of the solutions has very nearly been the same as that of water and the mass-scattering coefficients of light substances within wide limits are independent of the 
wave-lengths, as shown by the experiments of Barkla. When making controlling experiments, the absorption vessels being placed at a distance of $16 \mathrm{~cm}$. from the ionization-chambers, the same values of $\rho$ have, within experimental error, been observed.

Although the equation (1) whence (4) is deduced only holds when the radiation is homogeneous, this formula, according to Barkla's law, confirmed by various experiments (pp. 472-473) must hold as well when non-homogeneous radiation is used, supposing that the wave-lengths of the rays are not the same or nearly the same as those of the characteristic radiation of the element to be examined, and that rays of too great a wave-length are not used.

In the radiation used by the author from a bulb with an anticathode of tungsten, and with a spark-gap of at least $10 \mathrm{~cm}$, the rays have been filtered through an aluminium screen $1.25 \mathrm{~mm}$. thick. By the heterogeneous radiation, the rays of a greater wave-length have thus been filtered away, and the rest must certainly have got a decided maximum of intensity. When heterogeneous rays from a bulb with a spark-gap of some centimetres are transmitted by an aluminium screen sufficiently thick, the passing rays may practically be considered as homogeneous*. When changing the spark-length at the bulb, there has not in any case been observed either in lighter or heavier substances any influence on the determinations of the relative atomic absorption coeffieients. Within the range of the wave-lengths used by the author, the determinations of these coefficients are independent of the wave-length, and thus Barkla's law must be applicable.

By determining in the ordinary way the thickness of the aluminium sheet necessary to diminish the ionization by about half, the absorbability of radiation could, by means of formula (1), approximately be determined. Thus the approximate wave-length could be evaluated + , and as a mean value $\lambda=0.35 .10^{-8}$ was obtained. Among the substances examined certainly $W$, and probably also Ce and Ba, have entered into the range of selective absorption.

The rays $I$ have made use of have not been homogeneous, it is true, but in determining $X$. a. k., with regard to absorption for different sheet thicknesses, they have behaved in the same way as if they had been homogeneous. Indeed, it appears

* Compare Kaye, 'X-Rays' London, 1914, p. 103.

† Barkla and Dunlop, Phil. Mag. xxxi. p. 229 (1916). 
from the experiment, exhibited in the following table, that $X . a . k$. for aluminium is independent of the thickness of the absorbing screen.

TABLE II.

\begin{tabular}{|c|c|c|}
\hline $\begin{array}{c}\text { Thickness of } \\
\text { aluminium screen } \\
\text { in cm. (a). }\end{array}$ & $\begin{array}{c}\text { Thickness of } \\
\text { water sheet in } \\
\text { cm. }\left(d_{2}-d_{1}\right) .\end{array}$ & $\begin{array}{c}\text { X. a. k. } \\
\left(d_{2}-d_{1}\right) 55.5\end{array}$ \\
\hline $0 . \mathrm{m}$. \\
0.09 & 0.38 & 3.5 \\
0.11 & 0.60 & $3 \cdot 7$ \\
0.25 & 0.71 & $3 \cdot 6$ \\
& 1.51 & 3.3 \\
\hline
\end{tabular}

In the following table there is exhibited as a proof a series of observations, respecting absorption in aqueous solutions of $\mathrm{KCl}$ of various concentrations.

\section{TABLE III.}

\begin{tabular}{|l|c|c|c|c|}
\hline & $\begin{array}{c}\text { Number of } \\
\text { Spec. weight. }\end{array}$ & $\begin{array}{c}\text { Thickness of water sheet } \\
\text { in cm. }\left(d_{2}-d_{1}\right) .\end{array}$ & \multirow{2}{*}{ X. m. k. } \\
& $\begin{array}{c}\text { Kram-molecules pr l.(m.). } \\
\text { KCl }\end{array}$ & obs. & corr. & \\
\hline 1.1515 & 3.59 & 1.06 & 1.18 & 18.2 \\
1.1260 & 2.84 & 0.98 & 1.07 & 20.9 \\
1.1088 & 2.46 & 0.87 & 0.94 & 21.3 \\
1.0897 & 2.02 & 0.67 & 0.73 & 20.0 \\
1.0740 & 1.68 & 0.56 & 0.61 & 20.1 \\
1.0540 & 1.22 & 0.49 & 0.52 & 23.6 \\
1.0396 & 0.89 & 0.27 & 0.29 & 18.3 \\
1.0189 & 0.43 & 0.16 & 0.18 & 23.2 \\
\hline
\end{tabular}


The agreement between the values of $X . m . k$. found in the various concentrations (which in other experiments have, as a rule, been greater than in the above instance), is, as is shown here, rather good. The special values, from which the average values of Table IV.are calculated, generally differ at the most by 5 per cent. from the average numbers. The values of X. m. k., measured after this method, are, as shown in Table III., within experimental error independent of concentration in the solutions to be examined, apart from colloidal solutions. The fact is that for solutions that are strongly bydrolyzed, and then partly pass into a colloidal state, e.g. $\mathrm{FeSO}_{4}$ that has been oxidized by the contact of air, $\mathrm{Na}_{2} \mathrm{HAsO}_{4}$, \&c., absorption increases with increased dilution, about which see further on (p. 485). The concentration of the examined solutions has mainly been chosen so that $\left(d_{2}-d_{1}\right)$ has, at the utmost, reached about $1.5 \mathrm{~cm}$. by the way of avoiding the correction necessitated if the position of the comparator is too much changed relatively to the bulb.

When elements insoluble in water have been investigated, especially organic fluids whose absorption is less than that of water, another absorption vessel containing a water sheet of $1 \mathrm{~cm}$. thickness has been placed before the absorption vessel. Then absorption has been examined when this vessel has been empty, as well as when it has been filled with a liquid. After reading the thickness of the water sheet $\left(d_{2}-d_{1}\right)$ in the comparator, we directly find the thickness of the water sheet that corresponds to a sheet of liquid in question $1 \mathrm{~cm}$. thick. In examining absorption for metals, the procedure has been similar.

\section{Results of Experiments.}

The following table gives a survey of the values of X. m.k. I have found when examining the solutions named in the table. For each substance, as a rule, I have carried out 6-8 determinations with various concentrations or, if this has not proved possible, several determinations for the concentration, and the values seen in the table are average values of these determinations. 
TABLE IV.

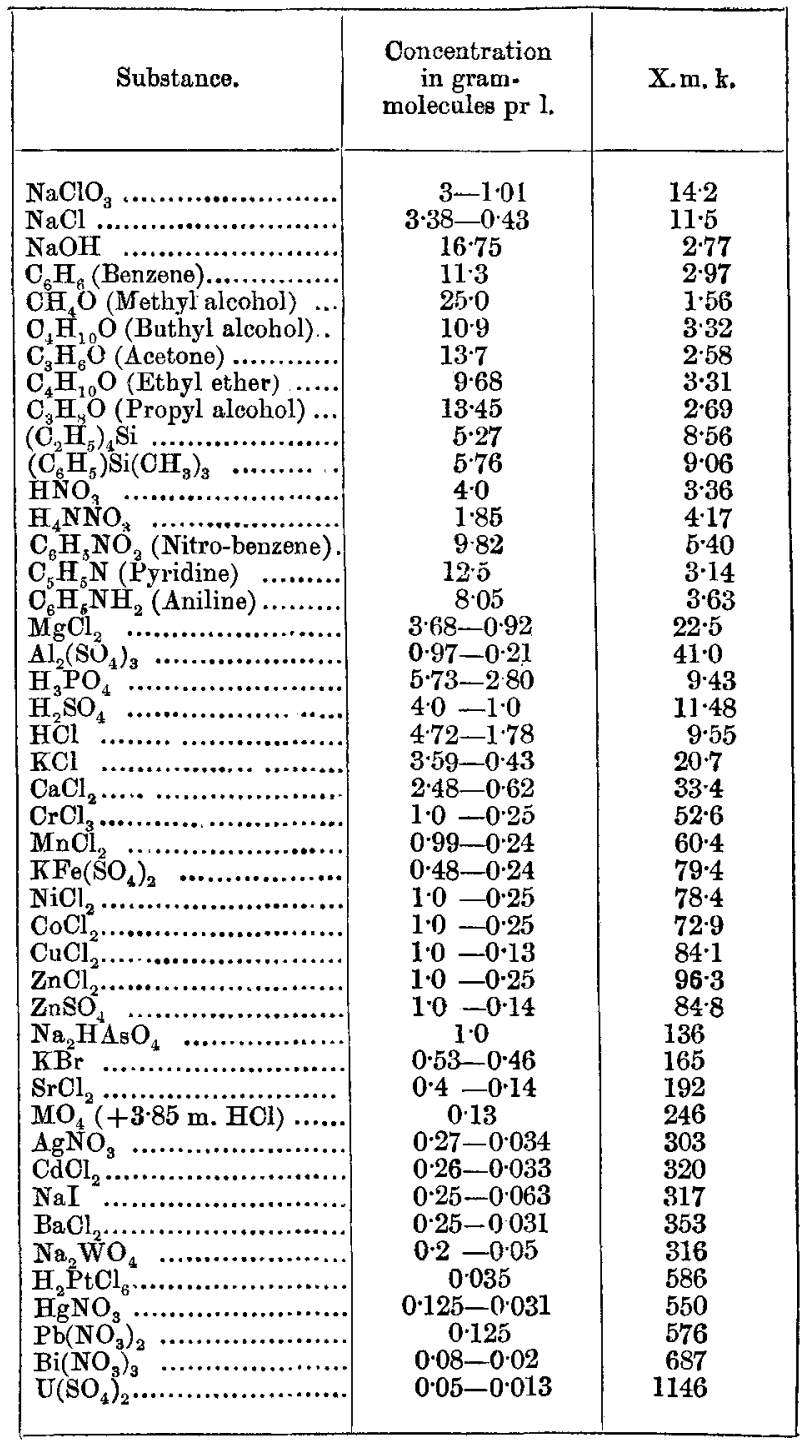


Table V. shows a survey of the values of X.a.k. I have found when examining metals in a solid state.

Table V.

\begin{tabular}{|c|c|c|}
\hline Metal. & $\begin{array}{l}\text { Thickness of } \\
\text { metal sheet } \\
\text { in } \mathrm{cm} .\end{array}$ & X.a.k. \\
\hline Al .. & $0.06-0.25$ & 3.5 \\
\hline $\mathrm{Fe}$ & 0.005 & $47 \cdot 3$ \\
\hline $\mathrm{Ni}$ & 0.01 & $57 \cdot 0$ \\
\hline $\mathrm{Cu} . . .$. & 0.006 & $65 \cdot 4$ \\
\hline Sn ......... & 0.0047 & 311 \\
\hline
\end{tabular}

The relative atomic absorption coefficients of the elements that are components of the combinations seen in Table IV. have been calculated and brought together in Table VI. In these calculations, I have started from the values of $X$.a.k. for oxygen and hydrogen, which are readily obtainable from the determinations of $\mathrm{X}$. m."k. for $\mathrm{NaClO}_{3}, \mathrm{NaCl}$, and $\mathrm{H}_{2} \mathrm{O}$. The difference between the values for the former combinations is 2.7 ; and as this difference depends on 3 atoms of oxygen, the X.a. k. of oxygen will be $0 \cdot 9$. Since X. m. k. of water is $1 \cdot 0$, we likewise find the value of $X$. a. k. of hydrogen to be 0.05. By the intermediary of the values of oxygen and hydrogen, we can then easily find $\mathrm{X}$. a.k. for Cl from $\mathrm{HCl}$, for $\mathrm{S}$ from $\mathrm{H}_{2} \mathrm{SO}_{4}$, for $\mathrm{N}$ from $\mathrm{HNO}_{3}$, \&c., whereupon the values of X. m.k. for the combinations X.a.k. for the other elements have been calculated in the same way. After examining two or more substances, from which the value of X. a.k.for a certain element has been calculated, the especial values as well as the mean value have been given. The table, moreover, gives the so-called atomic numbers, in which case I have used the numbers that of late years have been in co mmon practice (Moseley, Rutherford, \&c.).

Apart from the deviations in Co and W, X.a.k. steadily increases along with the increasing atomic weight.

As to the deviation for $W$, it certainly depends, as shown before, on selective absorption. In relation to. $\mathrm{X}$-rays, $\mathrm{Ni}$ appears to occupy the place between $\mathrm{Co}$ and $\mathrm{Cu}$, accordingly not the place due to its atomic weight*, and from a chemical

* Compare Pohl, Die Physik der Röntgenstrahlen; Moseley, Phil. Mag, xxvi. p. 1031 (1913); Barkla, Phil. Mag. xiv. p. 408 (1907). 
Table VI.

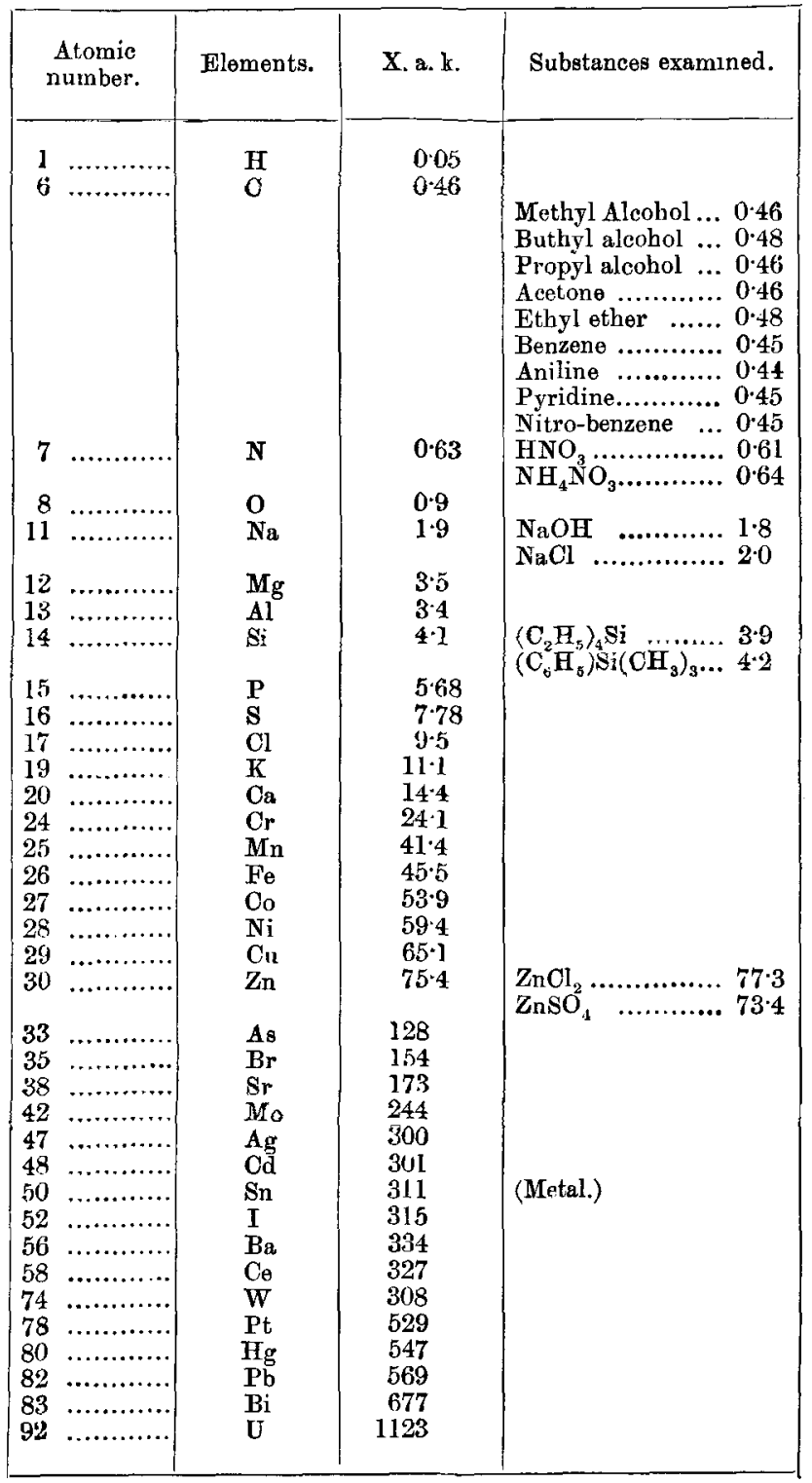


point of view, there seem to be various reasons why the former place should be appropriate to $\mathrm{Ni}$ in the periodical system. $\mathrm{X} . \mathrm{a.k}$. for $\mathrm{Ni}$ being greater than for $\mathrm{Co}$, is consequently in in good agreement with what is hitherto known about this metal. For $\mathrm{Mg}$ and $\mathrm{Al} \mathrm{I}$ have found approximately the same value of $X . a . k$., but this certainly depends upon an experimental error, and even a slight one can in this case he rather mischievous, first because the difference between $X$.a.k. for both metals is a slight one, and again because $\mathrm{X} . \mathrm{m} . \mathrm{k}$. of the respective salts is mainly determined by the acid radicals.

From the Tables V. and VI. it appears that X.a.k. for Al, $\mathrm{Ni}, \mathrm{Fe}$, and $\mathrm{Cu}$ has got very closely the same value, whether the values are calculated from the experiments on the respective elements in the metallic state or in the form of salts. From the values for $\mathrm{Na}$ and $\mathrm{Zn}$ it is clear that $\mathrm{X} . \mathrm{a.k}$. is, within experimental error, independent of any chemical combination the constant may be deduced from. These experiments consequently confirm what has been generally admitted in regard to absorption of $X$-rays: that it does not depend on any state of aggregation or any way of chemical combination.

In the following table there are given the values found by the author for X.m.k. for a solution of $\mathrm{FeSO}_{4}$ of different concentrations, with the calculated values of $\mathrm{X}$.a.k. for $\mathrm{Fe}$; $X . m . k$. of the $\mathrm{SO}_{4}$ ion being, according to the values in in Table VI., $11 \cdot 4$.

\section{TABLE VII.}

\begin{tabular}{|c|c|c|c|}
\hline $\begin{array}{c}\text { Number of } \\
\text { gram-molecules } \\
\text { per l. }\end{array}$ & $\begin{array}{c}\text { Thickness of } \\
\text { water sheet } \\
\left(d_{2}-d_{1}\right) .\end{array}$ & X. m. k. & X.a.k. \\
\hline 1.08 & 1.03 & 53.0 & 41.6 \\
0.81 & 0.78 & 53.4 & 42.0 \\
0.54 & 0.55 & 56.5 & 45.1 \\
0.41 & 0.42 & 56.8 & 45.4 \\
0.27 & 0.28 & 57.6 & 46.2 \\
0.133 & 0.14 & 58.4 & 47.0 \\
\hline
\end{tabular}

From the table we see that while concentration is decreasing, the value of $X . \mathrm{m} . \mathrm{k}$. is continually increasing, which seems to be owing to the fact that the salt, being 
oxidized by the contact of air and hydrolyzed by dilution, partly passes into a colloidal state. As I pointed out earlier, other solutions, that behave in the same way when diluted, display the same property with respect to absorption. The cause of absorption being greater in colloidal solutions seems to be the fact that, as shown by Galecki *, the number of particles irradiating a colloidal solution by X-rays is strongly diminished, in which process part of the radiation energy is required for the disintegration of the particles.

When values for bivalent $\mathrm{Fe}$ have been found in greater concentrations, they seem to be more exact than those found at a greater dilution. The mean value, $41 \cdot 8$, of the two first determinations is considered to give the probable value of X.a.k. for bivalent $\mathrm{Fe}$, this value, however, seems to be in reality somewhat too high. The difference between this and the value of trivalent $\mathrm{Fe}, 45 \cdot 5$, found on examination, is scarcely within experimental error, and, therefore, bivalent $\mathrm{Fe}$ is likely to have a lower absorption coefficient than trivalent $\mathrm{Fe}$.

X. a. k. of carbon from cyclic combinations (benzene, aniline, pyridine, nitro-benzene) seems to get a lower value than tbat of carbon from the alifatic sories, which fact may be traced to some difference in the inner structure of the two kinds of carbon. Since, however, as it appears from the figures quoted, a slight uncertainty with respect to X.a.k. of the elements forming combinations with carbon may in a high degree influence the results, there cannot, it seems, at present be drawn any trustworthy conclusions from the differences that have been observed in the measure of the absorption coefficients for different organic combinations. By continued researches the author hopes to be enabled to elucidate this question. As the sensibility of the methods used here can be increased, it will be possible to increase the exactness in determining the relative absorption coefficients.

In the same range of ideas, it seems worth noticing that the error in the values found for X. a.k. must be regarded as greater for the elements calculated from combinations whose X.m.k., estimated in percentage, is mostly determined by other component parts of the combinations, e. $g$. $\mathrm{Na}$ from $\mathrm{NaCl}$ and $\mathrm{Al}$ from $\mathrm{Al}_{2}\left(\mathrm{SO}_{4}\right)_{3}$.

The comparative slightness of the error is made plain by the good agreement between the values deduced from the above combinations as well as from the same elements in other combinations or in form of metals, e.g. for $\mathrm{Na}$ from $\mathrm{NaOH}$ and for Al from aluminium metal.

* Kolloidal. Z. x. p. 149 (1912). 
From the different values of $X$.a.k. I have tried to ascertain for different elements, there is evidence for believing that there exists a simple relation between the above-named quantity for a certain element and the atomic weight or atomic number. According to Bragg and Pierce, the atomic absorption coefficient is thought proportional to the fourth power of the atomic number (3), but after the results brought out by my experiments this cannot hold. Since Bragg and Pierce have only tested a few elements, the lack of agreement in this respect between their results and mine will be easily explicable.

Fig. 2.

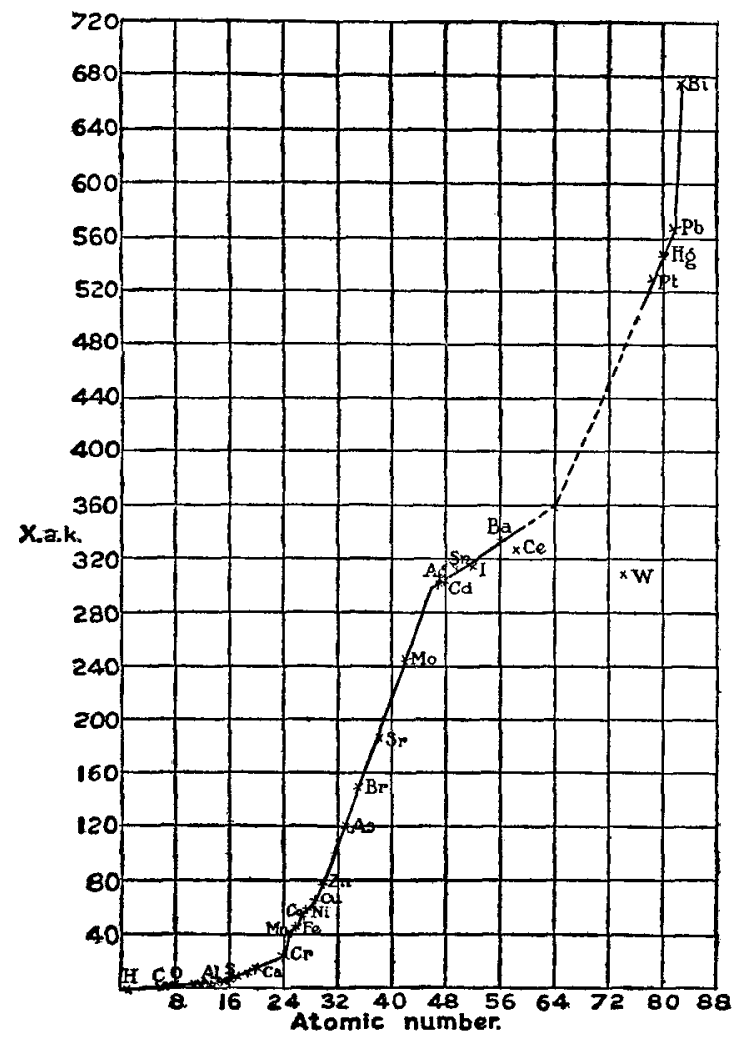

The connexion between $X . a . k$. and the atomic number is graphically brought out in fig. 2 , where the atomic number put as abscissa, and the corresponding value X.a.k. (TableVI.) as ordinate. The curve displays the values of $X$. a. k., arranged 
in groups, in which the especial values are proportional to the atomic number. Thus the relation between the different groups, on the other hand, appears slightly more complicated.

The elements $\mathrm{H}-\mathrm{N}, \mathrm{O}-\mathrm{P}, \mathrm{S}-\mathrm{Cr}, \mathrm{Mn}$ and $\mathrm{Fe}$, Co and $\mathrm{Ni}$, $\mathrm{Cu}-\mathrm{Pd}$ seem to form fairly well-marked groups. A new group seems to begin at $\mathrm{Ag}$; the elements $\mathrm{Pt}-\mathrm{Pb}$ seem to belong to a special group, which also seems to be the case with the element $U$. In order to try to determine whether the atomic absorption coefficient even under other experimental conditions, may be arranged into the same groups, especially at a radiation more homogeneous than that used here, and also with rays of differing hardness, the experiments will be continued.

Stockholm, Nobel Institution for Physical Chemistry.

XLVI. Normal Anomalies of the Mean Annual Temperature Variation. By HeNryk ArCTOWski*.

THE curves representing annual variations of atmospheric 1 temperature are generally derived from monthly means. For many stations, belonging to different climates, these curves convey the impression of representing a cyclic variation, reflecting, with different amplitudes and more or less retardation, the seasonal changes of solar declination.

If, in the case of long series of observations, instead of monthly means, the averages for each day of the year are taken into consideration, the diagrams thus obtained display most remarkable anomalies. As typical examples I would refer to the curves of Konigsberg, Munich, Catania, and Valentia, published by Van Rijckevorsel $\dagger$, and to the curve derived from observations made in Melbourne, published by R. J.A. Barnard $\ddagger$. Because of its simplicity, the Melbourne curve may be taken as a demonstrative example of the problem in view.

From the highest mean temperature, observed in January, the means decrease more or less regularly till the middle of March ; then, suddenly, temperature increases about $2^{\circ} \mathrm{F}$. Another characteristic break occurs between June 15th and 20th. After the minimum of July the increase of temperature is again interrupted in September and also at the end of November.

* Communicated by the Author.

† Phil. Mag. ser. 5, vol. xlv. p. 459 (1898).

$\ddagger$ Phil. Mag. ser. 5, vol. 1. p. 408 (1900). 